\begin{tabular}{|c|c|c|c|}
\hline 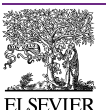 & Opinion & TRENDS in Biotechnology Vol.22 No.5 May 2004 & $\begin{array}{l}\text { Full text provided by www.sciencedirect.com } \\
\text { science Direct. }\end{array}$ \\
\hline
\end{tabular}

\title{
Biotechnology, bioethics and anti-aging interventions
}

\author{
Leigh Turner ${ }^{1,2}$ \\ ${ }^{1}$ Institute for Advanced Study, School of Social Science, Princeton, NJ 08450, USA \\ ${ }^{2}$ Biomedical Ethics Unit, Department of Social Studies of Medicine, Faculty of Medicine, McGill University, 3647 Peel Street, \\ Montreal, Quebec H3A1X1, Canada
}

\begin{abstract}
Careful analysis of the ethics of research on mechanisms of aging needs to recognize the complexity of human biology. Many contemporary bioethicists and policy-makers are exploring the ethics of 'anti-aging' interventions; however, current ethical analysis of biomedical research into disease processes and aging mechanisms is dominated by hyperbolic commentary. Numerous analyses in the bioethics literature mention the topic of anti-aging interventions and then leap to reflections on the banality of immortality. There is, however, no persuasive scientific evidence to suggest that humans are on the verge of becoming 'posthuman immortals'. Thoughtful ethical analysis of contemporary biomedical research ought to avoid philosophical and rhetorical excesses. We need more temperate discussions of current developments in biotechnology.
\end{abstract}

Leading bioethicists are currently expressing serious reservations about the long-term ethical and social consequences of various research initiatives in biotechnology. In particular, they are critical of efforts to develop anti-aging interventions. Critics of efforts to increase human longevity are responding to developments in various areas of research in the life sciences. In particular, they are reacting to research programs related to regenerative medicine, stem-cell therapies, telomerase and efforts to mimic the effects of caloric reduction [1-4].

\section{Critics of anti-aging interventions}

Opponents of efforts to extend human longevity are convinced that research in various scientific fields will eventually lead to substantially prolonged lives and considerable changes in human development and the life cycle, social institutions, economic structures and family life. Several commentators argue that medical research is driven by fantasies concerning complete control over life and death.

Leon Kass, Chairman of The President's Council on Bioethics (http://bioethics.gov/), is a trenchant critic of what he regards as a misguided quest to seek immortality through biomedical technologies. He states that "victory over mortality is the unstated but implicit goal of modern medical science, indeed of the entire modern scientific project, to which mankind was summoned almost four hundred years ago by Francis Bacon and Rene Descartes" [5].
Daniel Callahan argues that contemporary biomedical researchers are driven by a quest to vanquish death and eliminate finitude from the human condition. He traces the contemporary desire to overcome mortality to Francis Bacon, Rene Descartes and enlightenment proponents of science and progress. Callahan writes that "hardly anyone speaks of immortality as the aim, but that is beside the point; it is built into the research imperative... what is the battle against all known lethal diseases other than a kind of trench warfare against death itself?" [6].

Francis Fukuyama claims that "the medical profession is dedicated to the proposition that anything that can defeat disease and prolong life is unequivocally a good thing" [7]. Fukuyama, author of Our Posthuman Future: Consequences of the Biotechnology Revolution and a member of the President's Council on Bioethics, argues that efforts to increase human longevity risk undermining social security schemes, damaging family structures and social hierarchies, extending the lives of powerful tyrants, and rendering the United States vulnerable to assault by countries with more youthful populations (see pp. 57-71 in [7]). He suggests that developments in biotechnology could lead to a 'posthuman future', where human existence would be radically different from what we currently experience.

The President's Council on Bioethics report Beyond Therapy: Biotechnology and the Pursuit of Happiness (http://bioethics.gov/reports/beyondtherapy/index.html) considers whether we ought to accept the notion of a natural human lifespan, examines the possible personal, social and economic outcomes of anti-aging interventions, and suggests that efforts to control aging are connected to the desire to seek immortality [8]. References to significant increases in human longevity and the prospect of 'immortality' can be also found in newspapers and magazines [9-12]. Intermixed with sensible commentary about the possible effects of anti-aging interventions are far stranger remarks about how contemporary medical research is obsessed with making humans immortal. Little evidence is provided in support of this analysis of the goals of medicine and the life sciences.

\section{Life extension enthusiasts}

Meanwhile, as critics of anti-aging interventions challenge efforts to seek significant gains in human longevity, proponents of 'anti-aging medicine' tout innumerable 
products on the Internet [13,14]. Organizations such as the American Academy of Anti-Aging Medicine (http:// www.worldhealth.net/) and the Life Extension Foundation (http://www.lef.org/) market their products to individuals eager to postpone the effects, or at least the observable physical manifestations, of aging. Much like the critics of anti-aging medicine, members of these organizations seem convinced that immortality is just a decisive breakthrough away in research. But the products promoted by these groups have no credible scientific basis: there are no proven, scientifically established 'antiaging' medications [15-18].

\section{Temperate and intemperate ethical and social analysis}

Critics of anti-aging interventions make several important points: for example, significant extension of the human lifespan would radically alter human existence. Pension plans, social security schemes and notions of working lives would need to undergo major reformulation if humans lived considerably longer lives [19]. Reproductive practices and child-rearing patterns would have to change in societies where human longevity was greatly increased.

Critics of anti-aging interventions make important observations about how social institutions, notions of personal identity and economic structures would all change if humans lived greatly extended lives. I am concerned, however, that the critics of anti-aging interventions place too much emphasis on problems associated with radical life extension and even 'immortality'. Discussions of antiaging interventions that emphasize the topic of immortality skew analysis by moving from legitimate concerns to a far more speculative, less biologically grounded mode of deliberation.

Current debate on anti-aging interventions would benefit from paying greater attention to the short-term, more plausible implications of anti-aging research. Although we should acknowledge the possibility that advances in medicine and the life sciences might lead to innovative new therapies, we should focus on realistic situations and pay far less attention to more speculative, biologically implausible possibilities. We should follow Kass and Fukuyama in situating current research programs in biotechnology and the genetics of aging within a broad frame of ethical, social, legal and economic analysis [20]. We should assess carefully the long-term consequences of particular research agendas.

Yet, recognizing the importance of asking broad questions about the meaning of human existence, the organization of societies, and relationships among generations, contemporary critics of anti-aging interventions place too much emphasis on the prospect of substantial increases in human longevity. Many commentators dedicate a great deal of effort to describing how immortality would render human existence banal. But there is a profound difference between developing more effective biomedical interventions and making humans 'immortal'.

\section{Ethical analysis and human biology}

Neither proponents nor opponents of anti-aging interventions explain precisely how we are supposed to proceed from existing biomedical knowledge to some 'posthuman' condition. Commentators typically offer no concrete discussion of the biomedical technologies that are supposed to enable us to become the new Methusulahs. There is a great deal of magical thinking on all sides of the current debate concerning anti-aging interventions. Very little of this magical thought is connected to a firm grasp of the likely course of biomedical research and development.

\section{Why careful ethical analysis is needed}

Casual discussion of immortal life or significantly extended lifespan has at least three dangers. First, there are a great many anti-aging nostrums being marketed that have no demonstrable effects on slowing or halting aging [21]. Discussions of anti-aging interventions that take for granted the 'fact' that effective anti-aging techniques are imminent risk feeding further the hyperbole surrounding dubious nostrums. Biogerontologists, geneticists, bioethicists and policy-makers need to better protect citizens from potentially harmful, non-therapeutic and often costly products [22]. By using the language of 'immortality' and 'virtual immortality', bioethicists risk exaggerating the future course of biomedical research as they consider the possible effects of anti-aging interventions.

Second, humans live finite lives: there is no reason to think that humans are somehow about to become 'immortal' or 'posthuman'. Such terms sell books and newspapers; they do not correspond to the realities of contemporary biomedical research. On the contrary, even small increases in the lifespan of individuals with cancer or cardiovascular disease would constitute a noteworthy medical achievement. None of the rhetoric about enhancement therapies, cyborg bodies, posthuman bodies and the slowing or retarding of aging acknowledges the reality of mortality, the complexity of illness and aging, or the many obstacles facing researchers seeking to develop effect treatments for age-related diseases. By focusing on the prospect of substantial gains in human longevity and even immortality, current ethical analysis of anti-aging interventions underestimates the complexity of human biology and the challenges of developing effective, safe medical interventions.

Third, if critics of anti-aging interventions focus on only worst-case scenarios and extreme developments, important research into the genetics of age-related disease might be curtailed. Potentially, anti-aging interventions could have a role in developing better treatments for arthritis, osteoporosis and arteriosclerosis. Some anti-aging interventions could lead to undesired, potentially harmful outcomes; others might generate considerable benefits. By focusing on problems associated with substantial gains in human longevity, critics of anti-aging interventions neglect the possibility of therapeutic gains. Many researchers are currently searching for specific 'drugtreatable targets' related to human aging. A better understanding of various pathways might enable the development of pharmaceutical interventions that are useful in the treatment of neurodegenerative disease, cancer and cardiovascular disease. There is no need to equate treatment of these ailments with the quest to become immortal. Such claims caricature the work of researchers. 
Progress in various research domains is likely to be incremental in nature. Generating public controversy by focusing primarily on the dangers of 'immortality' and substantially extended lives risks undermining research that might play an important role in treating many different diseases [23]. We need more temperate commentary on the potential ethical, social and legal ramifications of research on the biology of aging. Instead of philosophical reflections on the banality of immortality or the spiritual vacuity of substantially extended lives, we need much more careful analysis of particular interventions. Hormone replacement therapy, for example, is hardly the success story that it was once touted to be. We need careful studies that try to estimate the short-term and the longterm effects of specific interventions.

\section{Conclusion}

Admittedly, we should recognize that incremental scientific advances could eventually lead to significant changes in human experience. Furthermore, developments in biomedical research are unpredictable. But humans are capable of adapting to changing circumstances. If life expectancy rates continue to increase gradually in developed nations, pension plans, retirement ages and social welfare schemes can be all adjusted to acknowledge evolving circumstances. Social institutions, political systems and patterns of family life are adaptable. We should not let exaggerated rhetoric and futuristic portrayals of the bleakest dystopian scenes deter us from acknowledging the human capacity to reconfigure social institutions in a creative, fair and sensible fashion. Contemporary research seeking to understand better the biology of aging need not culminate in a Blade Runner world [24].

There is much to be learned from fostering a wideranging debate about the goals of clinical medicine and life sciences research. However, we should ensure that we connect our rhetoric and moral deliberation to realistic conceptions of human biology [25-31]. Extended reflections on immortality suggest philosophical gravitas, but they provide little insight into how to set priorities or assess the merits of specific interventions. If we are going to have an expansive discussion of anti-aging medicine, we need more careful assessments of biomedical technologies and fewer grand pronouncements about the desirability or undesirability of achieving immortality. We need more temperate commentary from bioethicists: we need to challenge the hyperbole of utopian and dystopian thinkers and examine more carefully the benefits and burdens that particular biomedical interventions are likely to generate.

\section{References}

1 De Grey, A.D.N.J. et al. (2002) Is human aging still mysterious enough to be left only to scientists? BioEssays 24, 667-676
2 Lin, Y.J. et al. (1998) Extended life-span and stress resistance in the Drosophilia mutant methuselah. Science 282, 943-946

3 Helfand, S.L. and Inouye, S.K. (2002) Rejuvenating views of the ageing process. Nat. Rev. Genet. 3, 149-153

4 Partridge, L. and Gems, D. (2002) Ageing: a lethal side-effect. Nature 418,921

5 Kass, L. (2001) L'Chaim and its limits: why not immortality? First Things 113, 17-24

6 Callahan, D. (2000) Death and the research imperative. N. Engl. J. Med. 342, 654-656

7 Fukuyama, F. (2002) Our Posthuman Future: Consequences of the Biotechnology Revolution, Farrar, Straus \& Giroux

8 The President's Council on Bioethics, (2003) Beyond Therapy: Biotechnology and the Pursuit of Happiness, Regan Books

9 Kolata, G. (1999) Pushing limits of the human lifespan. New York Times, 9 March, D1-D2.

10 Wade, N. (1998) Intimations of immortality. Globe and Mail, 18 April, D8

11 Kevles, D. (1999) Preparing for the 200-year-old human. Globe and Mail, 17 March, A10

12 Wade, N. (1998) Immortality of a sort, beckons to biologists. New York Times, 17 November, D1-D2

13 Binstock, R. (2003) The war on 'anti-aging medicine'. Gerontologist 43, 4-14

14 GAO (2001) Anti-Aging Products Pose Potential for Physical and Economic Harm (GAO-01-1129), U.S. General Accounting Office

15 Binstock, R.H. et al. (2003) Anti-aging medicine and science: an arena of conflict and profound societal implications. Geriatrics and Aging 6, $61-63$

16 Butler, R.N. et al. (2002) Is there an antiaging medicine? J. Gerontol. Med. Sci. 57A, B333-B338

17 Fisher, A. and Morley, J.E. (2002) Antiaging medicine: the good, the bad, and the ugly. J. Gerontol. Med. Sci. 57A, M636-M639

18 Olshansky, S.J. et al. (2002) Position statement on human aging. J. Gerontol. Biol. Sci. 57A, B292-B297

19 Hayflick, L. (2000) The future of ageing. Nature 408, 267-269

20 Juengst, E.T. et al. (2003) Antiaging research and the need for public dialogue. Science 299, 1323

21 Wick, G. (2002) 'Anti-aging' medicine: does it exist? A critical discussion of 'anti-aging health products'. Exp. Gerontol. 37, 1137-1140

22 Special Committee on Aging, United States Senate (2001) Swinders, Hucksters and Snake Oil Salesmen: Hype and Hope Marketing AntiAging Products to Seniors. U.S Government Printing Office, Washington Serial No. 107-14

23 Miller, R.A. (2002) Extending life: scientific prospects and political obstacles. Milbank Q. 80, 155-174

24 Dick, P.K. (1982) Blade Runner (Do Androids Dream of Electric Sheep?), Del Rey

25 Shapin, S. and Martyn, C. (2000) How to live forever: lessons of history. Br. Med. J. 321, 1580-1582

26 Le Bourg, E. (2003) Gerontologists and the media in a time of gerontology expansion. Biogerontology 1, 89-92

27 Le Bourg, E. (2000) Gerontologists and the media: false hopes and fantasies can be dangerous for science. Biogerontology 1, 371-372

28 Strohman, R.C. (2001) Genomics and human life span - what's left to extend? Nat. Biotechnol. 19, 195

29 Olshansky, S.J. et al. (2001) Prospects for human longevity. Science 291, 1491-1492

30 Juengst, E.T. (2002) Growing pains: bioethical perspectives on growth hormone replacement research. J. Anti-Aging Med. 5, 73-79

31 Nelson, H.D. (2002) Assessing benefits and harms of hormone replacement therapy: clinical applications. J. Am. Med. Assoc. 288, 882-884 